DOI: https://doi.org/10.5007/1980-3532.2017n17p84

\title{
Da representação à participação: uma inflexão entre autores representativistas
}

\author{
From representation to participation: a change among \\ representative democracy authors
}

\author{
Gustavo Venturelli \\ Universidade Federal de Santa Catarina \\ Mestre em Sociologia Política \\ ledegout@gmail.com
}

\begin{abstract}
Resumo: Este artigo, dentro do debate mais amplo da teoria democrática, apresenta as ideias de Pitkin (1967, 2006), Manin (1995, 1997) e Dahl (2005, 2012) sobre o conceito de representação, os princípios do governo representativo e as instituições representativas, respectivamente. Por mais que esses autores tenham se debruçado com afinco sobre esta instância da vida e teoria políticas, trabalhos posteriores dos mesmos apontam para preocupações sobre o que é tratado, usualmente, como seu extremo oposto: a participação. Assim, apresentamos também as contribuições dos autores voltadas à democracia participativa (PITKIN; SCHUMER, 1982), os modos de participação não institucionalizados (MANIN, 2013) e a igualdade política (DAHL, 2006). Constata-se que há uma inflexão da representação à participação por parte desses autores, assim como a literatura da área tem mostrado, também, uma inflexão contrária, isto é, da participação e deliberação em direção à representação, constatada em alguns estudos (ROMÃO, 2011; GURZA LAVALLE; ISUNZA VERA, 2011).
\end{abstract}

Palavras-chave: Representação. Participação. Democracia.

Abstract: Within the democratic theory debate, this article aims to show the ideas of Pitkin $(1967,2006)$, Manin (1995, 1997) and Dahl $(2005,2012)$ about the concept of representation, the principles of representative government and the representative institutions. These authors have studied the representation throughout their academic lives, but in their late works, they have shown concern on participation, usually taken as the opposite of representation. Thus, we present their contributions on participatory democracy (PITKIN, SHUMER, 1982), non-institutionalized participations ways (MANIN, 2013) and political inequality (DAHL, 2006). We observe that there has been a displacement from the representation to participation in their works, as there also has been a change from participation to representation in those authors who have studied democracy from participatory and delibertive democracies (ROMÃO, 2011; GURZA LAVALLE; ISUNZA VERA, 2011).

Key-words: Representation. Participation. Democracy

Originais recebidos em: 23/09/2017

Aceito para publicação em: 04/05/2018

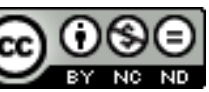

Este trabalho está licenciado sob uma Licença Creative Commons Atribuição-Uso NãoComercial-Vedada a criação de obras derivadas 3.0 Unported Licens

Revista Em Debate (UFSC), Florianópolis, volume 17, p. 84-106, 2017. ISSNe 1980-3532 


\section{Apresentação}

Quando falamos em democracia, na atualidade, nos referimos quase sempre à democracia representativa. Bobbio (1986) sistematiza o debate sobre a representação em duas questões: a primeira questão diz respeito ao tipo de mandato, isto é, se este deve ser imperativo (o representante é um delegado que figura como porta-voz do eleitorado) ou fiduciário (o representante tem liberdade de ação, levando em conta o que considera ser o interesse dos representados). A segunda questão refere-se àquilo que deve ser representado e apresenta duas respostas centrais: 1) deve-se representar interesses segmentados, como de classe, do distrito pelo qual o representante foi eleito, interesses étnicos, de gênero, etc.; 2) deve-se representar o interesse geral da nação, enquanto corpo político unificado.

Destas questões desdobra-se um outro problema, que busca compreender como as respostas dadas às questões supracitadas se cristalizam em instituições através das quais se representa o conjunto de cidadãos e através das quais é possível mediar a relação entre representantes e representados. Diversos autores debruçam-se sobre este tema apresentando distintos arranjos possíveis para essas questões. Alguns buscam defender a restrição da participação popular e dar ênfase às instituições que sejam desprendidas da opinião pública e funcionem de forma independente (SCHUMPETER, 1984). Outros defendem outro modelo de democracia e apontam arranjos ou princípios normativos que devem guiar a vida pública (PATEMAN, 1970; MACPHERSON, 1978; HABERMAS, 1995). Há, ainda, autores que buscam apontar para a superação do tratamento dicotômico entre representação e participação, buscando meios de mostrar as possibilidades da complementaridade entre os dois modelos (URBINATI, 2006). Esta busca por um modelo democrático capaz de se configurar a partir de dois modelos e princípios usualmente tratados de forma antagônica faz com que o conceito de representação ganhe novos significados.

Apesar de todo este debate mais amplo, neste artigo nos restringiremos a apresentar autores (PITKIN, 1967, 1982, 2006; MANIN, 1997, 2013,; DAHL, 2005, 2006, 2012) que tiveram como foco de suas preocupações a representação e passaram a dar mais abertura à participação em seus trabalhos ulteriores. Assim, dividiremos este trabalho em duas breve seções: a primeira apresenta as considerações e conceitos desenvolvidos por esses autores no âmbito da representação. A segunda seção busca dar 
conta de como o elemento participativo passou a ser tratado por esses autores em seus trabalhos mais recentes, apontando uma inflexão que vai da representação à participação em cada um deles. Por fim, apresentaremos as considerações finais, mostrando como o inverso também é verdade. Isto é, que entre autores contemporâneos que tiveram trajetórias marcadas por reflexões sobre participação política e instituições participativas, também há uma renovação do debate na medida em que passam a considerar o aspecto da representação em suas discussões, apontando para uma tendência geral na literatura que é a do tratamento não dicotômico entre representação e participação, mas sim enquanto duas instâncias ou ações políticas que podem e devem se complementar.

\section{Representação: ideias, princípios e instituições}

Se na Grécia Antiga nem toda decisão era tomada via assembleia e determinados assuntos eram resolvidos por pequenos corpos, através de representantes escolhidos via sorteio (MANIN, 1997), não seria correto afirmar que haveria, também, um conceito de representação definido à época (PITKIN, 1967). De acordo com Pitkin (1967), representação é um termo moderno, ainda que em seu sentido etimológico tal palavra já aparecera antes. Obviamente, a leitura de cada um dos autores que trataremos neste artigo sobre haver ou não representação na Grécia Antiga é distinta. Se os dois já citados parecem concordar que nem tudo eram flores, Dahl (2012), apesar de reconhecer o caráter exclusivo ${ }^{1}$ da democracia grega, parece ser partidário da leitura que considera tal modelo como ideal de democracia, sendo nossas experiências contemporâneas aproximações perversas deste modelo, motivo pelo qual opta por chamá-las de poliarquias (DAHL, 2005).

Cada um desses autores sistematiza seus escritos sobre representação de forma distinta. Pitkin (1967), mais voltada às ideias, apresenta o termo relacionado a tipos de representação. Manin (1997), por sua vez, desenvolve sua discussão em torno de princípios do governo representativo. Por fim, Dahl $(2005,2012)$ concebe as poliarquias em termos de instituições básicas que caracterizam um regime como democrático. Veremos, sucintamente, como cada um dos autores desenvolve suas ideias.

\footnotetext{
${ }^{1}$ Excluía mulheres, escravos e metecos.
} 
Em The concept of representation, Pitkin (1967) apresenta quatro visões da representação: formalista, descritiva, simbólica e substantiva. A visão formalista dividese em duas: a) como autorização, cujo principal formulador é Hobbes (1996) e na qual o representante é autorizado a agir por outros; b) accountability, cuja ideia básica é a da prestação de contas do representante para com os representados, a possibilidade do eleitorado punir (não reelegê-lo) ou recompensar (reelegê-lo) o representante ao fim do mandato e a ação do representante levando em conta os interesses dos representados (responsividade). A noção de representação descritiva nos remete a ideia de espelho, isto é, que a imagem do lócus onde se dá a representação e seus integrantes seja um reflexo preciso da sociedade e sua diversidade. A representação simbólica se dá através da utilização de símbolos que buscam tornar presente algo que, fisicamente, não está. Mas também diz respeito a representação de sentidos através de símbolos (a cor vermelha é historicamente associada à esquerda). Por fim, a representação substantiva tem a ver com o conteúdo da representação. Isto é, indaga-se, para além da autoridade ou direito de agir por outrem, sobre o que é feito através da representação.

Pitkin (1967) argumenta que todas as definições acima são insuficientes. A visão formalista seria insuficiente pois não questiona se um agente eleito representa bem ou mal, mas simplesmente se ele está autorizado ou não a agir ou se ele presta contas ou não ao fim do mandato. A autora defende que é necessário que a representação seja substantiva e, ao que tudo indica, esta definição cai no rol da insuficiência pois ela não pode ser a única característica da representação. Sobre a representação descritiva, Pitkin (1967) é simples e direta: seria impossível uma correspondência plena entre representantes e representados. A representação simbólica, que se funda num estado mental de identificação das vontades entre governantes e governados, é insuficiente pois isso não pode ser considerada representação e, no máximo, poderia se tornar uma teoria fascista da representação (PITKIN, 1967).

Essas críticas fundamentam a noção desenvolvida pela autora (1967), para quem a representação é uma atividade de agir por outros, cujas principais características são a equivalência entre representantes e representados e a exigência de que o representado esteja presente, de alguma forma, nas ações representativas. De acordo com Loureiro (2009:69), “a questão da equivalência na relação de representação é construída para desmontar a controvérsia mandato-independência", ainda que não haja a intenção de 
superar tal paradoxo. Mais do que isso, ele deve ser preservado como meio de garantir a independência tanto dos representantes como dos representados.

Em Principles of representative government, Manin (1997) busca sistematizar os aspectos que caracterizam o governo representativo. Observando que existiam instâncias de representação na Grécia Antiga, cujos membros eram eleitos via sorteio, Manin destaca o primeiro elemento que diferencia aquele tipo de representação do existente em democracias contemporâneas:

\footnotetext{
the fact that representative governments have never used lot to assign political power shows that the difference between the representative system and the "direct" system has to do with the method of selection rather than with the limited number of those selected. What makes a system representative is not the fact that a few govern in the place of the people, but that they are selected by election only (MANIN, 1997:41)
}

Ou seja, a principal característica deste tipo de governo é o método de escolha dos representantes e não a representação como forma de ação política.

Manin (1997) argumenta que o governo representativo passou por transformações ao longo da história, e que todas essas mudanças foram amplamente compreendidas como crises de representação. Para o autor, não trataram-se de crises, mas de metamorfoses do governo representativo. Apesar de suas transformações, o governo representativo manteve intactos seus princípios: 1) os representantes são eleitos pelos governados; 2) os representantes conservam uma independência parcial diante das preferências dos eleitores; 3) a opinião pública sobre assuntos políticos pode se manifestar independentemente do controle do governo; 4) as decisões políticas são tomadas após debate (MANIN, 1995, 1997). Construindo três tipos-ideais de governo representativo, o parlamentar, a democracia de partido e a democracia de audiência, Manin analisa como cada princípio se (re)configura em cada tipo-ideal de governo representativo.

Sobre a escolha dos representantes, Manin (1997) afirma que no modelo parlamentar ela se dá por conta da notoriedade ou status social. Os eleitores buscam representantes que lhes inspirem confiança. A extensão do sufrágio faz surgir os partidos de massa, de modo que o voto passa a ser dado em relação ao partido (democracia de partido). Os partidos criam clivagens eleitorais que refletem, em alguma 
medida, clivagens socioeconômicas ${ }^{2}$, levando os eleitores a votar nos candidatos de partidos cujas propostas estão próximas de seu segmento social. A democracia de audiência, caracterizada pela mídia e pelas habilidades midiáticas dos candidatos, faz com que as pessoas voltem a votar em indivíduos, e não em partidos. Neste modelo, a identidade partidária se dissolve, de forma que os resultados entre uma eleição e outra são bastante inconstantes e imprevisíveis.

Sobre o caráter do mandato, Manin argumenta que no modelo parlamentar o mandato é independente e o representante toma decisões de acordo com sua própria consciência. Na democracia de partido, a independência é da cúpula do partido, que através de negociações em busca de coalizões e aumento de sua força política definem um programa e orientam o voto dos demais. Por fim, na democracia de audiência os representantes são independentes, mas têm suas decisões fortemente influenciadas por imagens (MANIN, 1997).

O terceiro princípio diz respeito à liberdade de opinião pública e ganha sentidos diferentes em cada tipo-ideal. No modelo parlamentar, questões referentes à liberdade (de expressão, religiosa, etc.) não são resolvidas através de voto, mas a partir de pressão extraparlamentar. A falta de congruência entre a opinião dos representantes e representados faria com que o povo manifesta-se diretamente contra o parlamento (MANIN, 1995, 1997). Na democracia partidária há concordância entre a opinião dos representantes e representados, pois os partidos utilizam-se da imprensa partidária para influenciar a formação da opinião pública. Liberdade da opinião pública ou de expressão, aqui, significa liberdade de oposição, isto é, que dissidentes em relação ao governo possam circular suas opiniões contrárias e críticas direcionadas às políticas colocadas em prática. Na democracia de audiência a mídia não tem caráter partidário (MANIN, 1995). As opiniões entre representantes e representados também não coincidem e os mecanismos centrais para se estabelecer o que são as opiniões de ambos são os surveys ou pesquisas de opinião.

\footnotetext{
${ }^{2}$ Esta é uma explicação exógena a um fenômeno ou instituição política. Isto é, busca argumentar com elementos externos à própria política, como clivagens de classe ou culturais, o surgimento de partidos políticos. Para um visão endógena (ALDRICH, 1995), partidos são criações internas, i.e., são criados por necessidades existentes no interior da política institucional, como dificuldades em tomar decisões (problemas de coordenação), redução da incerteza, redução do custo na formação de coalizões, etc. Ou seja, partidos são criados para resolver problemas internos ao próprio Congresso.
} 
Por fim, o último princípio refere-se ao debate parlamentar. No primeiro modelo, como o mandato é livre, o parlamento é um espaço de deliberação perfeito: somente após a discussão e a troca de argumentos é que os representantes tomam as decisões através do consenso da maioria. Na democracia de partidos as decisões são tomadas internamente nos partidos e o parlamento só figura como palco da agregação das opiniões para ver qual delas tem mais adeptos. No último modelo, o Parlamento tem pouca influência nas decisões, pois, como os eleitores apresentam baixos índices de identificação e filiação partidária, os representantes falam a eles diretamente, através dos meios de comunicação de massa. Portanto, as negociações são entre o governo e grupos de interesses externos ao Parlamento (MANIN, 1997).

De acordo com o argumento de Manin, a ideia de crise de representação deve-se à confusão de que sendo a representação uma forma de democracia (democracia indireta), a superação da crise demanda democracia direta (LOUREIRO, 2009). Portanto, visto que Manin é dos autores que distingue democracia de governo representativo, não são crises representativas ${ }^{3}$, mas apenas processos em que ocorrem metamorfoses do governo representativo.

Para Dahl (2005, 2012), são as ideias e instituições representativas que tornam possível a transposição da ideia de democracia para os Estados nacionais modernos, amplos em território e contingente populacional. Assim, diante da impossibilidade técnica de exercer o ideal democrático grego nas sociedades contemporâneas - não há como todos os cidadãos decidirem sobre todos os assuntos conjuntamente -, Dahl elabora sua teoria a partir da junção dos ideais democráticos e da ideia de representação.

De acordo com Dahl (2012), as democracias modernas estão baseadas na Grécia Clássica, na tradição republicana, nas ideias e instituições representativas e na lógica da igualdade política. Indo direto à ideia que nos interessa, a das ideias e instituições representativas, Dahl afirma que é a junção da prática da representação com as ideias democráticas que faz a democracia tomar outra forma. Tal forma se distancia do ideal democrático grego, o que leva o autor adotar o termo poliarquia para referir-se às experiências democráticas modernas.

\footnotetext{
${ }^{3}$ Esta afirmação é possivelmente contra-argumentada. Uma possível crise do governo representativo (ou dos sistemas eleitoral e partidário) poderia ser afirmada levando em conta os baixos índices de comparecimento eleitoral e os níveis irrisórios de filiação ou identificação partidária (SAMUELS; ZUCCO, 2013).
} 
As poliarquias representam o modelo mais próximo que se chegou, até hoje, de uma democracia e seu sucesso depende de suas instituições. A poliarquia pode ser entendida como "um conjunto de instituições necessárias ao processo democrático em grande escala" (DAHL, 2012:346-347). Estas instituições permitem aos cidadãos a satisfação de três condições básicas dos regimes democráticos. Isto é, os cidadãos devem ter a possibilidade de formular suas preferências, exprimi-las e as terem consideradas igualmente pelo governo na formulação das políticas. Para isso, as instituições necessárias à poliarquia são:

1) Funcionários eleitos. Os funcionários eleitos são constitucionalmente investidos do controle político das decisões governamentais.

2) Eleições livres e justas. Os funcionários eleitos são escolhidos em eleições frequentes, conduzidas de modo justo, nas quais a coerção é relativamente rara.

3) Sufrágio inclusivo. Praticamente todos os adultos têm o direito de votar na eleição dos funcionários do governo.

4) Direito de concorrer a cargos eletivos. Praticamente todos os adultos têm o direito de concorrer a cargos eletivos no governo, embora os limites de idade possam ser mais altos para ocupar o cargo do que para o sufrágio.

5) Liberdade de expressão. Os cidadãos têm o direito de se expressar, sem o perigo de punições severas, quanto aos assuntos políticos de uma forma geral o que inclui a liberdade de criticar os funcionários do governo, o governo em si, o regime, a ordem socioeconômica e a ideologia dominante.

6) Informação alternativa. Os cidadãos têm o direito de buscar soluções alternativas de informação. Ademais, existem fontes de informação alternativa protegidas por lei.

7) Autonomia associativa. Para alcançar seus vários direitos, inclusive aqueles relacionados acima, os cidadãos também têm o direito de formar associações ou organizações relativamente independentes inclusive partidos políticos independentes e grupos de interesse.” (DAHL, 2012:350-351).

Além da satisfação das três condições supracitadas, o autor (2012) destaca que essas instituições ainda satisfazem a igualdade de voto; a participação efetiva; a compreensão esclarecida; o controle da agenda; e a inclusão.

A teorização de Dahl sobre a democracia e as instituições necessárias à poliarquia gira em torno de duas dimensões teóricas: a contestação pública, que tem a ver com a possibilidade de se fazer oposição ao governo; e a participação, referente à inclusão dos cidadãos na vida pública do país ${ }^{4}$. É de acordo com o nível destas duas variáveis que se pode dizer que um sistema é mais (ou menos) democrático. Além disso, a responsividade parece ser, para este autor, característica central da democracia. Isto é,

\footnotetext{
${ }^{4}$ Buscar definir uma experiência democrática contemporânea nesses termos, de acordo com Miguel (2013:72), é uma "definição mínima, elegante e operacional, mas paga o preço de deixar muita coisa importante do lado de fora".
} 
o fato de os governantes terem de levar em conta, continuamente, as preferências dos cidadãos, buscando manter-se no poder ${ }^{5}$.

A partir da correlação entre a existência ou não de algumas ou todas as instituições necessárias à poliarquia e os níveis de contestação e participação, Dahl constrói, na análise de processos de transição de um regime político ao outro, uma tipologia de regimes, que tem em um extremo hegemonias fechadas, onde níveis de contestação e participação são baixos; e no outro, a poliarquia, com índices elevados de participação e contestação (DAHL, 2005).

Como o autor trata de transições e, grosso modo, suas comparações são entre regimes autoritários e regimes poliárquicos, Dahl defende abertamente as poliarquias. Por outro lado, o autor admite que as instituições poliárquicas não são modelos ideais e que não alcançaram o nível máximo de democratização que uma sociedade pode obter.

$\mathrm{Na}$ seção seguinte apresentaremos como esses três autores aqui debatidos apresentaram inflexões em direção à participação em suas preocupações. São trabalhos mais recentes e, ao que tudo indica, menos lidos e comentados.

\section{Da representação à participação}

Todos os autores apresentados na primeira seção tiveram como objeto central de suas reflexões a representação, seja no âmbito das ideias, dos princípios ou das instituições. Entretanto, em trabalhos ulteriores, todos eles voltaram suas reflexões para a participação. Com diferentes conotações, cada um deles tratou deste tema.

Em artigo escrito em coautoria, Pitkin e Shumer (1982) definem democracia fundamentando-se em ideias como capacidade de autonomia e autogoverno enquanto exercícios necessários para garantir a liberdade e o pleno desenvolvimento de cada indivíduo, assim como garantia de uma comunidade mais justa e livre.

A difundida convicção de que é impossível pôr em prática a democracia participativa estaria fundada em dois argumentos de uma visão liberal: por um lado, a visão instrumental que considera que política diz respeito unicamente a como, quando, onde e quem governa, onde políticos profissionais cuidam dos assuntos comuns e cada

\footnotetext{
${ }^{5}$ Tal definição do que objetiva um partido ou político está fundada na teoria da escolha racional: por um lado, em Downs (1999), para quem os partidos buscam cargos e para isso utilizam-se das eleições como meio; por outro lado, em Mayhew (1974), que buscando "limpar" sua análise sobre o congresso estadunidense, considera os congressistas como single-minded, isto é, com um único objetivo: a reeleição.
} 
indivíduo pode perseguir seus próprios interesses; por outro lado, esta mesma tradição afirma haver um bem-comum a qual cada indivíduo deve subordinar seus interesses particulares. Ambos tornam a democracia participativa inalcançável, pois o primeiro argumento exclui o cidadão de qualquer responsabilidade além do voto e o deixa livre para buscar seus interesses próprios; e o segundo apresenta-se como um sacrifício que cada indivíduo deve fazer, um peso do qual os cidadãos tentarão escapar pois a impressão que têm é que este bem-comum não lhes diz respeito (PITKIN; SHUMER, 1982).

As autoras (1982:44) afirmam que "Genuine and serious obstacles do challenge the realization of democracy today. But the notion that it is impossible is an illusion". Apresentam, assim, contra-argumentos aos autores que apontam para a impossibilidade da democracia por conta do tamanho dos Estados-nação ou por conta das qualidades necessárias aos cidadãos para se engajarem na vida pública.

Àqueles que argumentam sobre a impossibilidade técnica, Pitkin e Shumer (1982) afirmam que este é um argumento ingênuo, pois funda-se na ideia de que toda a população de uma nação deveria caber em uma assembleia. Mas não é disso que se trata a democracia participativa. Obviamente que

Face-to-face citizen assemblies are indeed essential to democracy, but one single assembly of all is not. Representation, delegation, cooperation, coordination, federation, and other kinds of devolution are entirely compatible with democracy, though they do not constitute and cannot guarantee it. (PITKIN; SHUMER, 1982:50).

As autoras citam a descrença de Michles (1982) em relação à democracia, quando o autor argumenta que toda organização tem a tendência de se burocratizar e hierarquizar, criando uma elite que ficará distante de suas bases. O fazem para contraargumentar que nenhuma mobilização espontânea e sem forma será a fonte de um enfrentamento à ordem estabelecida, que seja capaz de criar uma mudança duradoura. A chave seria "to develop those organizational forms and those styles of authority that sustain rather than suppress member initiative and autonomy" (PITKIN; SHUMER, 1982:51). Há exemplos históricos dessas formas de organização ${ }^{6}$ e eles devem servir de ponto de partida e inspiração para a criação de novos.

\footnotetext{
${ }^{6}$ Ver Pateman (1970), sobre as fábricas autogestionadas na Ioguslávia.
} 
A tarefa dos democratas seria pensar em instituições de poder coletivo em larga escala que sejam capazes de ser responsivas em relação às bases participativas. Instituições que garantam o diálogo entre representantes e representados, entre o local e o nacional. As autoras (1982) recorrem Tocqueville (2000, 2005), para argumentar que a democracia face à face é a base das instituições representativas, e não uma alternativa a ela. São em encontros deste tipo que os indivíduos desenvolvem as habilidades para a cidadania e o gosto por esta atividade ${ }^{7}$. É também em encontros desse tipo que se pode construir novas instâncias de representação mais legítimas.

Desfazendo o argumento da incapacidade do cidadão comum para os assuntos públicos, Pitkin e Schumer (1982) argumentam que em qualquer estrato social há pessoas com maior dificuldade para entender a coisa pública. O remédio não é excluílas do processo, mas sim incluí-las, ganhar com suas perspectivas e admitir que política não tem a ver somente com conhecimento, mas também com o que e como será feito. Portanto, a partir da diversidade de perspectivas chega-se a um consenso sobre o que será feito, para então contarmos com a expertise dos técnicos, capazes de aplicar o que as bases demandam. Os técnicos, na perspectiva das autoras, são parte e não uma alternativa ao processo democrático.

Assim, apresentam uma defesa parecida com a que há em Pateman (1970), que argumenta que a possibilidade de participar de tomadas de decisão deve estar em todos os âmbitos da vida de um indivíduo:

Democrats today must seek out and foster every opportunity for people to experience their own effective agency: at work, at school, in family and personal relations, in the community. Democratic citizenship is facilitated by democratic social relations and an autonomous character structure (PITKIN; SHUMER, 1982:52).

Mas se a participação só emerge de escalas muito pequenas, é possível pensarmos em uma democracia participativa em sociedades extensas como as nossas? As autoras argumentam que, se queremos tornar nossas sociedades democráticas a longo prazo, as mudanças devem começar nas bases.

Today's democrat must hope that in the brief experience of active participation that follows a flaring up of the democratic impulse, ordinary people, discovering the connections between local problems and national structures, coming up against the repressive power of established privilege, will themselves discover the need for more fundamental changes. We must

\footnotetext{
${ }^{7}$ Tal argumento está presente também em Pateman (1970).
} 
be prepared to use the impulses toward and the experience of democracy, where they occur and while they last, to produce the social and economic changes that will further facilitate democracy (PITKIN; SHUMER, 1982:53).

Citando os movimentos dos anos 1960, as autoras dizem que temos que aprender com seus os erros. Esses movimentos não viram a si mesmos como uma alternativa participativa que poderia trazer resultados significativos a longo prazo, e diluíram-se tão rápido quanto surgiram. Lutaram por pautas específicas e não tiveram "paciência democrática", isto é, a capacidade de estender um momento democrático por um tempo significativo (PITKIN; SHUMER, 1982). Quando escreveram o artigo, as autoras acreditavam que novos movimentos estavam surgindo e seriam eficazes em encorajar a autonomia, a participação a nível local e um desprendimento do sistema. Tais grupos deveriam criar laços com outros grupos que enfrentam a lógica do sistema e propõem alternativas, tendo sempre em conta que uma mudança estrutural significativa toma tempo, mas que a "democracy's full realization might well [...] abolishing private ownership of the means of production; or even abandoning the Faustian dream of mastering and exploiting nature to gain infinitely expanding wealth" (PITKIN; SHUMER, 1982:54). Não é porque este ideal estaria longe que estes movimentos deveriam deixar de pôr em prática arranjos de democracia participativa.

As autoras tinham uma noção de democracia participativa como fundamenta o governo representativo. Talvez o decorrer das décadas seguintes levou Pitkin (2006) a uma conclusão mais pessimista, ao afirmar que se a verdadeira função da política é

\footnotetext{
dirigir nossa vida pública compartilhada e se seu valor real reside na oportunidade de dividir poder e responsabilidade sobre aquilo que estamos fazendo conjuntamente como sociedade, então ninguém mais pode fazer minha política "por" mim e a representação pode significar apenas [...] a exclusão da maioria das pessoas dos benefícios da política (PITKIN, 2006:42).
}

Desta forma, a autora dá um fechamento mais enfático ao seu ensaio, fundamentando-se em Arendt (1965:240 apud PITKIN, 2006:43), para apresentar ao leitor as duas possibilidades que restam ao povo, frente à perversa forma como operam as instituições representativas: a “'letargia, precursora da morte da liberdade pública', ou deve 'preservar o espírito de resistência' diante de qualquer governo que tenha eleito, já que o único poder que conserva é 'o poder reserva da revolução"”. 
Manin (2013) concilia os princípios do governo representativo com as novas formas de se fazer política. O que faz em seu artigo é redefinir o que chamou de democracia de audiência, argumentando que neste tipo de governo representativo os partidos não se tornaram obsoletos. Partidos ainda são decisivos na democracia de audiência, apesar de não terem identidades bem definidas e duradouras. Para parte significativa do eleitorado eles tornaram-se instrumentos a serem utilizados a depender da conjuntura.

Ao lado dos baixos índices de fidelidade partidária, outra coisa que passou a chamar a atenção de Manin (2013) na democracia de audiência é o que o autor chama de formas não institucionalizadas de participação. Isto é, o crescente número de cidadãos que afirmaram ${ }^{8}$ participar de protestos, manifestações, assinar abaixoassinados, fazer greves não oficiais, ocupar edifícios de empresas ou do Estado, etc.

Tais formas de participação não institucionalizada caracterizam-se por: 1) ocorrerem de forma episódica, a partir de oportunidades ${ }^{9}$ criadas por conjunturas específicas. Desta forma, os participantes não têm qualquer vínculo identitário com um movimento particular para participar de tais ações, eles se engajam porque uma oportunidade se apresentou; 2) são episódios que têm causas específicas: as pessoas participam pois a ação gira em torno de uma questão de interesse pessoal para elas, não de um conjunto amplo de questões mais gerais; 3) são ações voltadas ao Estado e aos representantes, buscando influenciar as tomadas de decisão desses atores (MANIN, 2013).

Em vez de interpretar essas formas de participação política como crise da representação, Manin (2013) as considera como gatilhos de uma transformação da democracia representativa. Alguns críticos da democracia representativa veem a participação não institucionalizada como uma insatisfação com o governo representativo, resultando na transformação da relação entre cidadãos e Estado. Contudo, Manin (2013:125) enfatiza que esta transformação se deu no interior da “estrutura institucional das democracias representativas".

Citando Pipa Norris, para quem o aumento da participação através de outros meios foi capaz de rejuvenescer o governo representativo e capaz de canalizar as

\footnotetext{
${ }^{8}$ Os dados utilizados por Manin (2013) é da série organizada por Ronald Ingleheart, através do World Values Survey (WVS).

${ }^{9}$ Esta ideia, conforme referencia o autor (2013), baseia-se no conceito de estrutura de oportunidade política, de Tarrow (1998).
} 
demandas da base, Manin (2013) destaca que as democracias representativas foram capazes abrigar o aumento da participação não institucionalizada.

Não há incoerência entre a democracia representativa e a participação política não institucionalizada, pois o governo representativo nunca foi pensado como um sistema em que os representantes substituiriam os representados, que por sua vez só poderiam se manifestar nas eleições (MANIN, 2013). É um sistema que resguarda aos cidadãos o direito de se manifestar e fazer ouvir a qualquer momento. Manin elogia a flexibilidade do governo representativo, mostrando que a não rigidez de seus princípios possibilita um mandato independente. Ainda que os políticos devam ser responsivos aos eleitores, não quer dizer que seus mandatos devam ser delegados ou imperativos.

Por fim, Manin (2013) afirma que a possibilidade de coexistência do governo representativo e de formas de participação política não institucionalizada pode ser saudável à democracia, criticando o que considera os extremos da teoria democrática contemporânea:

\begin{abstract}
Grande parte da teorização que ocorre hoje sobre a democracia se baseia em uma distinção entre democracia schumpeteriana, na qual os cidadãos escolhem regularmente entre elites, mantendo-se quietos no meio-tempo, e democracia participativa, em que os cidadãos tomam decisões políticas em todos os momentos. Fazer a distinção entre esses dois tipos pode ser instrutivo, mas exclui a democracia representativa, que não é nenhum deles $\left(\right.$ MANIN, 2013:127) ${ }^{10}$.
\end{abstract}

Em seu último livro, On political equality, Dahl (2006) aponta os obstáculos à igualdade política. Assumindo como pressuposto que a igualdade política é um desejo e objetivo compartilhado pelos cidadãos de uma república democrática, Dahl passa a definir este princípio democrático em termos de condições para que seja alcançado; elenca os obstáculos para a realização deste objetivo; e aponta alternativas que produziriam uma mudança cultural e de valores entre os cidadãos americanos, capazes de impedir o aumento da desigualdade política e, de modo contrário, tornar mais tangível o objetivo da igualdade.

Uma democracia que pretenda garantir igualdade política entre seus cidadãos depende de um conjunto de característica: 1) participação efetiva: antes de uma política ser adotada, todos aqueles que serão atingidos por esta devem ter a possibilidade de se fazer ouvir; 2) igualdade no voto: nas tomadas de decisão todo membro deve ter igual e

\footnotetext{
${ }^{10}$ Tal definição de democracia participativa parece resultante de um interpresentação equivocada, pois sabe-se que não se trata disso. Instâncias de representação continuam a existir no interior deste modelo.
} 
efetiva oportunidade de votar; 3) entendimento esclarecido: cada membro deve ter iguais oportunidades de aprender sobre as alternativas para a política que está sendo votada; 4) controle de agenda: os membros devem poder decidir quando e o que será votado; 5) inclusão: todos os membros terão o direito de participar igualmente nos itens anteriores; 6) direitos fundamentais: a voto, à participação, de buscar a informação necessária para tomar uma decisão, etc. (DAHL, 2006).

Os obstáculos à igualdade política elencados por Dahl (2006) são seis. O primeiro seria a distribuição desigual de recursos, habilidades e incentivos políticos. Um recurso político é qualquer meio (dinheiro, tempo, informação, etc.) através do qual uma pessoa pode influenciar o comportamento de outra. Desde a compreensão sobre uma política pública até o uso da oratória para convencer, os recursos e habilidades são distribuídos desigualmente. Além disso, o engajamento na vida pública não depende só de habilidades e conhecimento, é necessário um incentivo - também distribuído de forma desigual -, para que um indivíduo torne-se uma pessoa pública.

O segundo obstáculo diz respeito ao dilema do tempo. Se todas as pessoas de uma unidade democrática extensa forem expressar suas opiniões antes de se tomar uma decisão, o governo ficará paralisado. Portanto, quanto mais pessoas uma democracia tiver, menos elas poderão participar diretamente das tomadas de decisão, tendo que delegar poder a outrem. A questão do tamanho (terceiro obstáculo) das democracias aparece novamente, aqui, observando-se que quanto menor uma unidade democrática, mais chances os cidadãos terão de participar dos momentos decisórios e, de modo contrário, quanto maior for a nação, menores serão possibilidades de participação direta.

A existência de uma economia de mercado (regulada ou não pelo Estado) que gera diversos problemas para significativa parcela da população, como pobreza, fome, desemprego, subemprego, etc., é o quarto obstáculo. Mesmo as economias de mercado consideradas mais "eficazes" ou "justas" geram desigualdades na distribuição de renda e da riqueza. Consequentemente, a posição que um indivíduo ocupa numa economia de mercado ou os ganhos que tem a partir dela lhe permite uma posição de maior ou menor influência no interior do campo político, gerando desigualdade política.

Outro obstáculo são os órgãos internacionais como a União Europeia, a Organização das Nações Unidas, etc. São órgãos supranacionais cujas decisões afetam cidadãos das nações que os compõem, sem que estes cidadãos sejam consultados sobre 
as matérias. Assim, os atores que integram esses órgãos detém muito mais poder político do que um cidadão comum dos países que os integram.

Por fim, as crises também são geradoras de desigualdade política. Dahl (2006) observa que de tempos em tempos todos os países enfrentam sérias crises institucionais, causadas por diversos motivos: desastres naturais, guerras, conflitos internos, desemprego, etc. Em momentos de crise, como por exemplo quando ocorrem ataques terroristas, a concentração de poder nas mãos do Executivo fica ainda mais evidente, de modo que este poder tomar decisões sem consentimento da população, inclusive decisões contrárias ao que deseja a maioria da população ou a oposição. São momentos que geram desequilíbrio na suposta igualdade política.

Dahl considera que a partir desses obstáculos é provável que a desigualdade política continue crescendo. Levando em conta o pouco tempo disponível que têm os cidadãos para participar da vida pública e o custo dessa participação para os estratos mais baixos, o autor soa pessimista. Outro problema seria a cultura de consumo alimentada pelo capitalismo, que espalha uma crença de que acesso aos bens de consumo representa melhoria de vida e bem-estar. Tal cultura seria alimentada pela inveja e sentimento de injustiça que nutrem os cidadãos de estratos mais baixos, ao verem outros indivíduos que lutaram tanto quanto eles alcançarem níveis econômicos e de satisfação superiores. Dahl (2006:90) afirma que a cultura da cidadania ${ }^{11}$ é muito fraca entre os americanos e que tal cultura seria fundamental, pois estimularia "a critical mass of citizens to place a much higher value on engaging in political life as a means for achieving their goals". Um desses objetivos seria, obviamente, maior igualdade política.

Apesar do evidente pessimismo, Dahl (2006) tenta mostrar uma luz no fim do túnel, perguntando-nos quem, no século XVIII, imaginaria que chegaríamos aos dias atuais com tantos direitos políticos. Lembra-nos, ainda, que lutas e esforços contra as injustiças do capitalismo continuam em cena. A partir disso, o autor aponta um conjunto de reformas que poderiam nos guiar para uma cultura cidadã.

Seria necessária uma reforma nas regras de financiamento de campanhas, que coloque claros limites às empresas, sindicatos e indivíduos. Limites que não permitam a

\footnotetext{
${ }^{11}$ Desde Tocqueville (2000) há um consenso quando se fala de uma forte cultura democrática e associativa nos Estados Unidos. No entanto, estudos mais recentes como o de Putnam (2001), não por acaso intitulado Bowling Alone, mostram que os níveis de associativismo - de todos os tipos, do recreativo ao político - caíram drasticamente durante os últimos anos nos Estados Unidos.
} 
dependência entre representante e financiador. Uma reforma eleitoral que melhore a participação dos eleitores e cidadãos, com tecnologias mais avançadas para controle dos votos, registros, pesquisas eleitorais, etc. Uma reforma na mapeamento dos distritos, isto é, um método que substitua e torne inconstitucional o gerrymandering ${ }^{12}$, que permite a manipulação dos desenhos dos distritos pelos governos estaduais a fim de garantir o controle de seu partido na House of Representatives. Acesso universal a um programa de saúde (Medicare). Além disso, um fundo de previdência para os mais pobres, aumento do salário mínimo, facilitação do acesso ao nível superior, entre outras (DAHL, 2006).

Estas mudanças diminuiriam a inaceitável desigualdade política entre os cidadãos americanos. $\mathrm{O}$ autor teme que a desigualdade política torne-se cada vez maior, podendo colocar em risco, em última instância, a própria democracia. Mas a discussão de Dahl em torno do problema da igualdade política não transcende a participação política relacionada às instituições estatais cristalizadas e convencionais. $\mathrm{O}$ autor pensa unicamente em mecanismos exteriores à própria política que seriam capazes de equilibrar o poder político entre os atores envolvidos nesta instância da vida e em um par de reformas no sistema eleitoral. Entretanto, não aponta para outros meios possíveis de se fazer política além do institucional.

Dahl (2006:106) afirma que "The cultural shift from consumerism to citizenship is more likely to come about, not because of the failure of market capitalism, but because of its success". Isso porque o capitalismo só seria capaz de satisfazer os indivíduos até certo ponto. Em países considerados ricos, o aumento da renda e riqueza depois de determinado nível não gera mais felicidade e bem-estar. Este seria o ponto a partir do qual a mudança poderia acontecer. Quanto mais americanos chegarem a essa mesma conclusão, mais eles irão buscar outros caminhos para satisfazerem-se. Tais caminhos existem e, conforme forem descobertos, a esperança do autor é que os cidadãos americanos tragam para suas vidas e para vida política americana algo que está em falta: "a stronger popular commitment to spend time and energy in order to secure the adoption of such policies" (DAHL, 2006:119). Tais políticas garantiriam avanços para o objetivo final: a igualdade política.

\footnotetext{
${ }^{12}$ Método utilizado para desenhar os distritos eleitorais nos Estados Unidos.
} 


\section{Considerações finais}

O debate sobre representação, seja em relação às ideias, aos princípios ou instituições, gera incontáveis controvérsias. Tal debate está presente em todos os lados e é um debate manifesto, que se desdobra em diversos outros problemas, como as questões relacionadas à corrupção, à desconfiança nos partidos e políticos, à não representatividade, aos índices de abstenção eleitoral bem como de votos nulos e brancos, etc. Fala-se também nas saídas desse lodo no qual as ideias e práticas se afogam: reforma política, aumento de formas de participação, etc. Tais esforços geralmente restringem-se ao meio acadêmico e, por mais que também estejam presentes em âmbito institucional, são processos que caminham muito lentamente.

Como vimos, autores que desenvolveram trabalhos seminais sobre o conceito ou o governo representativo, mostraram a necessidade de pensarmos como garantir a participação política nas experiências democráticas contemporâneas, sem com isso extirpar a representação como forma de ação política. Esta necessidade é uma necessidade urgente, pois se em nenhuma das democracias contemporâneas o povo governa, de fato, e as decisões são tomadas por minorias, é necessário entender do que se trata a representação, desde suas ideias, princípios, até suas instituições. Isto é, "o conceito de democracia precisa ser reconstruído" (MIGUEL, 2013:29).

A inflexão desses estudiosos da representação em direção à participação parece ser nesse sentido, de redefinir este conceito e repensar suas práticas representativas, mostrando que restringir-se ao âmbito da representação sem apontar e discutir os problemas que suas ideias e instituições encerram, é um grave equívoco, uma displicência ética e intelectual, pois ignora-se as desigualdades que este modelo pode reproduzir.

Como os autores debatidos aqui apresentaram inflexões da representação à participação, alguns autores das correntes participativas e deliberativas também apresentaram esta inflexão na direção contrária: da participação à representação. Geralmente, autores (FEDOZZI, 2001; AVRITZER; NAVARRO, 2003; BORBA; LUCHMANN, 2007) que trabalham a partir dessas correntes desenvolvem estudos de instituições específicas, caracterizadas como instituições participativas - Conselhos Gestores, Orçamentos Participativos, Conferências e Fóruns temáticos, etc. - regidas pelos princípios dos modelos participativo e deliberativo da democracia. 
As teorias participacionistas (PATEMAN, 1970; MACPHERSON, 1978) não negaram, em nenhum momento, a necessidade de instâncias representativas. Ainda que em Pateman (1970) a representação parece restringir-se àquele já admitida por Rousseau (2006), isto é, a imperativa/delegada, ela esteve presente em suas reflexões. Macpherson (1978), em seu modelo piramidal, também admite a necessidade da representação a nível nacional, principalmente na formulação da agenda a ser discutida pela base, o que pode ser problemático, visto que o controle da agenda é um dos problemas da desigualdade política, como vimos em Dahl (2006). Ou seja, "os autores 'participacionistas' propunham modelos bem mais complexos, que conservavam a representação política, mas combinavam-na com a gestão direta da base, esperando que esta última exercesse efeitos benéficos sobre a primeira" (MIGUEL, 2013:64). Mas a interpretação equivocada da democracia participativa como democracia direta, talvez tenha feito este modelo democrático ficar no canto do debate mais amplo das teorias democráticas, deixando o lugar de destaque aos deliberacionistas, corrente que ganhou diversos adeptos no Brasil e no mundo durante os anos 1990, e tem como principal expositor Habermas (1995).

Apesar do sucesso, os deliberacionistas figuram nestas considerações finais justamente pelo fato de já terem sido apresentando os limites da deliberação por uma série de autores (YOUNG, 1996; LUCHMANN, 2002; VIEIRA; SILVA, 2013; MIGUEL, 2013). O seu apreço pela razão e troca de argumentos nos espaços deliberativos, a fim de produzir consenso e resultados, ignora desigualdades sociais, culturais, educacionais, econômicas, de gênero, étnicas, etc., que não podem ser suprimidas com um simples princípio como "todos podem [e devem] discutir como se fossem iguais" (MIGUEL, 2013:69). Além disso, olvida-se que nem só de argumentos racionais são feitos os debates políticos. Demonstrações de paixão, emoções, irracionalidade, etc., são características evidentes nessas discussões, além de outras formas discursivas, como a retórica, a saudação, contar de histórias, etc. (YOUNG, 2006). Ademais, ao definir sua situação ideal de fala, Habermas (1995) argumenta que qualquer contribuição pertinente pode ser apresentada durante a discussão, aspecto este problematizado por Miguel (2013) com duas simples perguntas: pertinente para quem? Quem define o que é pertinente? O modelo habermasiano parece restringir-se à abstração, sem fazer uma ligação clara entre as ideias e a realidade, sem propor um desenho institucional de funcionamento dessas arenas e, talvez a falha mais gritante, 
apresentar um modelo de "comunicação face a face [...] impróprio para o entendimento da política, exatamente por descartar a questão da representação" (MIGUEL, 2013:75).

Talvez seja justamente por estas críticas e outras que não foram exploradas aqui que diversos autores (ROMÃO, 2011; AZEVEDO, 2012; LUCHMANN, 2014) que fundamentavam e ainda fundamentam suas pesquisas na teoria democrática deliberativa têm, cada vez mais, buscado compreender as instâncias de representação no interior das experiências participativas, apontando para suas limitações e contradições.

O fato é que os debates sobre representação, tanto no âmbito das ideias como no institucional, voltou à agenda e demanda um intenso debate e reformulação, pois muitas das definições apresentadas são insuficientes, assim como as instituições ainda parecem demasiado problemáticas e insatisfatórias. Alguns avanços significativos foram elaborados no sentido da superação do tratamento dicotômico entre representação e participação (GURZA LAVALLE; ISUNZA VERA, 2011; MIGUEL, 2005). Nesse sentido, a partir da inflexão em direção à participação por parte de autores amplamente conhecidos por estudos sobre a representação, buscou-se apontar a necessidade de complementaridade entre esses dois modelos, sem cair no argumento de que a representação é uma solução para os extensos e populosos Estados nacionais da modernidade (DAHL, 2012), no argumento minimalista ou elitista que reduz a democracia a um método de escolha das lideranças (SCHUMPETER, 1984), ou no extremo contrário da defesa de uma democracia direta, sem instâncias representativas.

Assim, consideramos essencial uma revisão refinada das ideias, práticas e instituições democráticas, buscando solucionar os problemas referentes à desigualdade política, restritos canais de participação, ao distanciamento entre representantes e representados, entre outros. Somente a partir da confluência desses dois lados da teoria democrática para um ponto em comum que será possível rearranjar nossas instituições e práticas de forma mais justa e igualitária, podendo redefinir os conceitos de democracia, representação e participação.

\section{Referências}

ALDRICH, J. Why Parties? The Origin and Transformation of Political Parties in America. Chicago: The University of Chicago Press, 1995. 
AVRITZER, L.; NAVARRO, Z. A inovação democrática no Brasil: o orçamento participativo. São Paulo: Cortez, 2003.

AZEVEDO, N. Orçamento participativo em face dos dilemas teóricos e práticos da democracia contemporânea: uma comparação das experiências de Belo Horizonte e Porto Alegre. Tese (Doutorado em Ciência Política), UFMG, Belo Horizonte, 2012.

BOBBIO, N. O futuro da democracia: uma defesa das regras do jogo. Rio de Janeiro: Paz e Terra, 1986.

BORBA, J.; LUCHMANN, L. H. H. (orgs.). Orçamento Participativo: análise das experiências desenvolvidas em Santa Catarina. Florianópolis: Insular, 2007.

BURKE, E. Discurso aos eleitores de Bristol. Revista de Sociologia Política, v. 20, n. 44,2012 p. $97-101$.

DAHL, R. A democracia e seus críticos. São Paulo: Martins Fontes, 2012.

Press, 2001.

How democratic is the American Constitution? New Haven: Yale University On political equality. New Haven: Yale University Press, 2006.

. Poliarquia: participação e oposição. São Paulo: Editora da Universidade de São Paulo, 2005.

DOWNS, A. Uma teoria econômica da democracia. São Paulo: Edusp, 1999.

FEDOZZI, L. Do patrimonialismo à cidadania - participação popular na gestão municipal: o caso do orçamento participativo de Porto Alegre. Dissertação (Mestrado em Sociologia), UFRGS, 1996.

GURZA LAVALLE, A.; ISUNZA VERA, E. A trama da crítica democrática: da participação à representação à accoutability. Lua Nova, São Paulo, n. 84, 2011, p. 95139.

HABERMAS, J. Três modelos de democracia. Lua Nova, n. 36, CEDEC, São Paulo, p. 39-54.

HAMILTON, A.; MADISON, J.; JAY, J. The Federalist Papers. New York: Bantam Books, 1982.

HOBBES, T. Leviathan. Oxford: Oxford University Press, 1996.

LOUREIRO, M. R. Interpretações contemporâneas da representação. Revista Brasileira de Ciências Sociais, Brasília, n. 1, jan.-jun. 2009, p. 63-93.

LÜCHMANN, L. H. H. 25 anos de Orçamento Participativo: algumas reflexões analíticas. Política \& Sociedade, Florianópolis, v. 13, n. 28, set/dez 2014. p. 167-197. 
- Possibilidades e limites da democracia deliberativa: a experiência do Orçamento Participativo de Porto Alegre. Tese (Doutorado em Ciências Sociais) UNICAMP, Campinas, 2002.

MACPHERSON, C. B. A democracia liberal: origens e evolução. Rio de Janeiro: Zahar, 1978.

MANIN, B. A democracia do público reconsiderada. Novos Estudos, São Paulo, n. 97, nov. 2013, pp. 115-127.

As metamorfoses do governo representativo. Revista Brasileira de Ciências Sociais, n.29, 1995, p. 5-34. 1997.

. The principles of representative government. Cambridge University Press,

MAYHEW, D. Congress: the electoral connection. New Haven: Yale University Press, 1974.

MICHELS, R. Sociologia dos partidos políticos. Brasília: Ed. Universidade de Brasília, 1982.

MIGUEL, L. F. Democracia e representação: territórios em disputa. São Paulo: Editora Unesp, 2013.

Impasses da accountability: dilemas e alternativas da representaçãopolítica.

Revista de Sociologia e Política, Curitiba, n. 25, nov. 2005, p. 25-38.

PATEMAN, C. Participation and Democratic Theory. Cambridge: Cambridge University Press, 1970.

PITKIN, H. F. Representação: palavras, instituições e idéias. Lua Nova, São Paulo, n. 67, p. 15-47, 2006.

The concept of representation. Berkeley: University of California Press, 1967.

PITKING, H. F.; SHUMER, S. M. On participation. Democracy, v. 2, n. 4, 1982, pp. 43-54.

Putnam, R. D. Bowling alone: The collapse and revival of American community. New York: Simon and Schuster, 2001.

ROMÃO, W. Conselheiros do Orçamento Participativo nas franjas da sociedade política. Lua Nova, São Paulo, n. 84, 219-244, 2011.

ROUSSEAU, J.J. O contrato social: princípios de direito politico. São Paulo: Martins Fontes, 2006.

SCHUMPETER, J. Capitalismo, socialismo e democracia. Rio de Janeiro: Zahar, 1984. 
TOCQUEVILlE, A. A democracia na América: leis e costumes. São Paulo: Martins Fontes, 2005. 2000 . A democracia na América: sentimentos e opiniões. São Paulo: Martins Fontes,

URBINATI, N. Representative democracy: principles and genealogy. Chicago: The University Chicago Press, 2006.

VIEIRA, M.; SILVA, F.C. Democracia deliberativa hoje: desafios e perspectivas. Revista Brasileira de Ciência Política, no10. Brasília, janeiro - abril de 2013, pp. 151-194.

YOUNG, I. Communication and the other: beyond deliberative democracy. In: BENHABIB, Seyla. Democracy and difference: contesting the boundaries of the political. Princeton: Princeton University Press, 1996. p. 120-136. 